\title{
A Study on Physical Protection Requirements for Game Based Learning (GBL) Management System
}

\author{
Tai-hoon Kim¹)
}

\begin{abstract}
Generally, programs that are based on games and used for learning are called as the form of educational games. Basically, because of the commonality of games, computer games and educational games use much the same technology and have similar functions. Computer games are designed mainly for leisure purposes, but educational games are designed for the transfer of knowledge. However, due to the commonality of games, each program has both educational and entertainment aspects. Game-based learning promotes experiential learning by making the content of learning fun like a game and by creating a virtual learning environment through motivation. Many researchers believe that learners can participate in learning more thoroughly by enjoying learning as a game. In this paper, author presents the noble ideas about the game based learning (GBL) management system for distance learning.
\end{abstract}

Keywords: Physical Protectionn, Securtiy, GBL, E-learning, Game based E-learning.

\section{Introduction}

Game-based education is a unique function that complements traditional teaching strategies, stimulates innovative thinking, and imparts diversity to teaching methods. Games provide learning concepts more interesting to students and provide a platform for learners to reflect their creative ideas[1]. Game-based learning (GBL) is a type of game play that has defined learning outcomes. Generally, game-based learning is designed to balance subject matter with gameplay and the ability of the player to retain, and apply said subject matter to the real world[2]. In the coming years, games and innovation are expected to be used in simulation of the real environment and real world issues. For example, in flight trainings, simulation in form of games is being used in actual preparation of the pilot to take off or going out the planes. This simulation could help reduce the stress and risk of performing the real scenario like flying. Professionals used the simulation-games in many areas. The Avaya and 3D simulation

Received(December 19, 2017), Review Result(1st: December 31, 2017, 2nd: February 2, 2018), Accepted(February 12, 2018)

1) (Professor) Dept. of Convergence Security, Sungshin W. University2, Bomun-ro 34da-gil, Seongbuk-gu, Seoul, Korea email: taihoonn@sunghin.ac.kr 
game has been used for the training of emergency responders and other agencies specifically on spy-themes learning game to improve their sales skills.

Visual and auditory stimuli were provided through video and podcasts, though not immerse three-dimension virtual world. Cultural awareness training is one of the scenario being tested by role-playing alien races from competing planets and for business plans, project management competencies is being used. To result with the high level learning competencies engagement, the participants are being immersed in repetitive engagement with the scenarios.

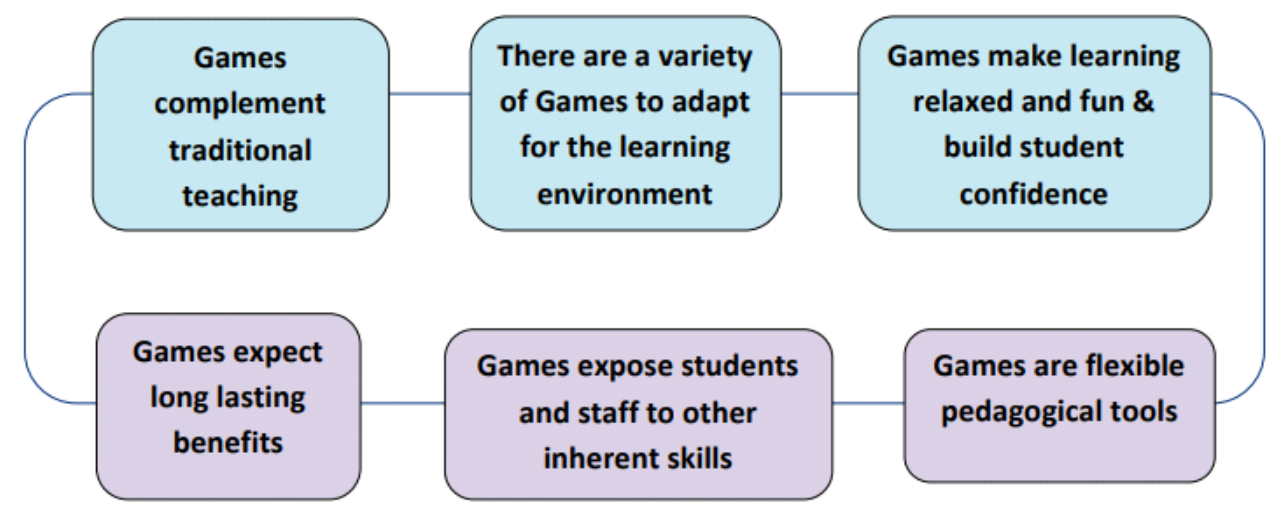

[Fig. 1] Overview of typical game based e-learning system

\section{Background of the Study}

The Serious Games' and 'Game-Based Learning' is overused and often in the wrong context. These terms are often employed as a justification to introduce digital games into the classroom or to sell a product that has little entertainment value. Digital games do have a place in the classroom, but as a tool to be utilized by creative teachers and not to replace teachers as suggested by some (Bushnell, 2009; Prenksy, 2004)[2].

Pivec and Pivec $(2009 \mathrm{~b})$ created a real-life role-play to teach design students at a university level, and subsequently turned it into a digital game by using an e-learning role-play platform. The scenario was fantasy and the platform provided rules, control, multiple forms of communication and feedback for both players and moderators[2].

Games are designed to have an educational purposes and application. Any type of games can be used as tools for educational environment. Educational games are designed to help people to learn certain subjects, explore concepts, help in development, understand a historical culture and events, as well as teaching them skills while they playing games. Board, cards, and 
video games are some of the game type that is being used. It is now mainstream on educators, governments, and parents as they realized the psychological need and benefits of games on learning. Interactive games teach us in achieving goals, rules, adaptation, problem solving, interaction represented as a story.

In order to design an appropriate game based-learning, the trainer should know first what are the learners needed to learn. The trainers may fail to design an appropriate game based learning if it can't connect to the learners. To avoid this, consider the demographics so that it won't be too difficult or too familiar. Early at the design process, it is better to gather ideas from the learners to get insights into what they want in technology in general or specific application, application-specific content-related preferences, the types of elements to be included in graphical user interfaces and the structure that the learners may like to personalize their applications. Multiplayer role playing games (MMO's) provide opportunities for players to improve their skills like critical thinking, complex learning, and other practices. It also provide collaborative gaming and learning through social network which contribute in the formation of teams and aid communication in the community.

Game-based learning presents a new educational approach that allows students to explore new knowledge in a learning environment designed by the instructor. Instructors and learners will experience new experiences through the game and will work together to add depth to their knowledge. With high-quality game-based learning applications, we can create a more familiar and relevant virtual environment for learning the same content.

The learner behaves towards the goals that the instructor presents in an effective game-based learning environment and experiences the consequences of those behaviors. Learners make mistakes in a risk-free environment and actively learn and practice on the right behaviors through experiments. This process allows learners to learn behavior and thinking that can be easily transferred from the simulation environment to the real environment.

\subsection{Benefits of digital game-based learning}

Technology is being used in school to solve problems in a more fun way specifically on mathematics. They usually come up with the case studies to introduce students to technologies with a goal to prepare them in future used of the particular technology. These technologies were also designed to work in virtual world. Recently, educational e-games are being developed for higher education learners in combination of real world and virtual world for 24/7 virtual educational experience. Common core standards are utilized by educators to 
supplement their teaching strategies and programs. According to non-profit organization ed tech-based, Common Core are being addressed with the help of e-games.

Patricia Deubel said that electronic game-based learning has a potential to engage and motivate learners and give custom learning experiences while giving long-term memory and supplementing real experience scenario. She also suggest that non-violent games is an effective game-based learning in a classroom setting to facilitate planning and problem-solving in relation to the curriculum. She also recommended role-playing, adventure simulation games because it appeals to the development of many skills. It also develop vocabulary skills and enhancement of mental alertness.

According to Mark Griffiths, there are seven electronic games which are great tools for conducting research. He quote that electronic games have 'great diversity', as well attracting learners with various demographic backgrounds. They also help students to achieve their goals, provide helpful feedbacks, save records for inventory and measurement purposes. He also suggested that interactive capabilities of electronic games stimulates learning and as weel encourage learners to open up new topics or ideas. Griffiths also notes that video games can help students develop computer skills that they may need in a society that continues to develop technologically.

\subsection{Limitations of digital game-based learning}

As is commonly known, game-based learning appears to have some benefits. However, to take advantage of these benefits, the program must look attractive to students, and the goals of the game must always be aligned with the learning goals of the education. When using a game program as an educational tool, Deubel suggests that the instructor should consider how the game's functioning can affect students cognitively and physiologically. The instructor must decide whether the content of the game is suitable for a particular age group and whether the game is suitable for responsible activity at a common sense level.

Griffiths points out that there are some drawbacks to using video games or digital games in the classroom. The most important disadvantage of digital-based games is that games are constantly upgraded. Therefore, the instructor must evaluate the educational impact of the game each time the game is upgraded, which is very difficult.

Instructors should also consider the amount of game-based instruction available in the school environment. In addition, some students may not be able to access this type of learning tool if the school does not have enough technology to support a digital game-based learning 
program.There are a lot of great gamification examples out there, from Deloitte adding badges and rankings to their digital Leadership Academy, to DuoLingo's usage of skill points when lessons are completed. Here are a few more examples to give you a taste for gamification in the real world:

\section{3. e-Learning Gamification Examples}

Gamification makes the learning process that the instructor proceeds in game format. By using the mechanics used in the game and the play elements used in the game for learning purposes, the learner is motivated and engaged more than the traditional learning process.

IBM's Kudos Badges:

Used for IBM Connections, Kudos Badges can be awarded to users based on custom adoption behavior (did they use the tool?) and also include leaderboards for some friendly competition, and profile progress for a sense of "leveling up."[4]

Quest to Learn:

An entire, gamified school, Q2L uses game design elements like levels, missions, and quests to keep students engaged with learning material. "Boss levels" replace finals as a way to test students' ability to apply acquired knowledge.[4]

Duolingo:

A good example of how far gamification can go to teach a challenging subject, Duolingo is a gamified language-learning website. By turning tests and lessons into challenges and keeping track of progress, Duolingo keeps learners engaged and motivated, even when they might otherwise be frustrated or bored.[4]

If a learner proceeds through the gamification process, game-based learning is not a complete education system, but rather a means of achieving a particular learning objective.

The following are the basic benefits of game-based learning[5][6]:

\section{a. Increases Memory Capacity}

A lot of games are often centered around the use of memorization. When you focus on these games, learners need to memorize important sequences or cues in order to solve a given problem in the game 


\section{b. Computer \& Simulation Fluency}

This is very important because we live in an era when we are dominated by technology. Today's learners are accustomed to the way they play games over the Internet. There are also websites like the Cartoon Network game that provide learners with interesting and exciting games. This allows young learners to learn how to use the mouse and keyboard, as well as basic information such as browsing, ID and password, and Internet browsing.

\section{c. Strategic Thinking \& Problem-Solving}

The recent games are designed to help learners to organize their thoughts and conclusions in a short period of time. Also, to solve a given problem, we ask the learner to make a logical judgment. Through these exercises, learners can develop their own logic, accuracy, and ability to think, which also helps with other learning.

\section{d. Hand-Eye Coordination}

Recently, games are meant to be played using the game pad, keyboard, and mouse. This allows learners to help hands and eyes co-ordinate. This training is effective not only for children, but also for the elderly who are weakened.

\section{e. For Attention Disorders}

Experiments with children and elderly people with attention disorders have shown that online games can solve this problem to a certain extent. This was announced by a team at Nottingham University and has been repeatedly proven in similar studies.

\section{f. Skill-Building (e.g. map reading)}

There are a variety of programs that are used to help people in specific situations or difficulties. For example, in an adventure game where many mysteries must be solved, the contents of the learner's guide are shown like a map. Doing these games actually helps to improve your thinking skills. In addition, games such as real estate management allow learners to experience financial management and general project management.

\section{Proposed E-learning}

In reality, when educators introduce game-based instruction into the curriculum, they must consider a lot of content. First of all, it is one of the most important factors for learners to 
adopt computer games as educational tools. Next, you need to consider the level of skills that support essential software, the essential knowledge that a teacher or facilitator must have, finance, and licensing issues to keep the game running smoothly. Educators should also think about meta games around the computer game itself and create activities that promote thought, communication, and collaboration.

The Training Room Platform (2009) is a well-known environment in which trainers define online role-playing scenarios and give learners the experience to apply factual knowledge and gain experience through the digital world. Trainers need to be able to define new games or adopt and modify sample games without knowing programming skills. This platform provides a variety of means of communication within the scenario during learning. Learners can conduct discussions, send and receive text, voice chat, and communicate with other learners through videoconferencing.

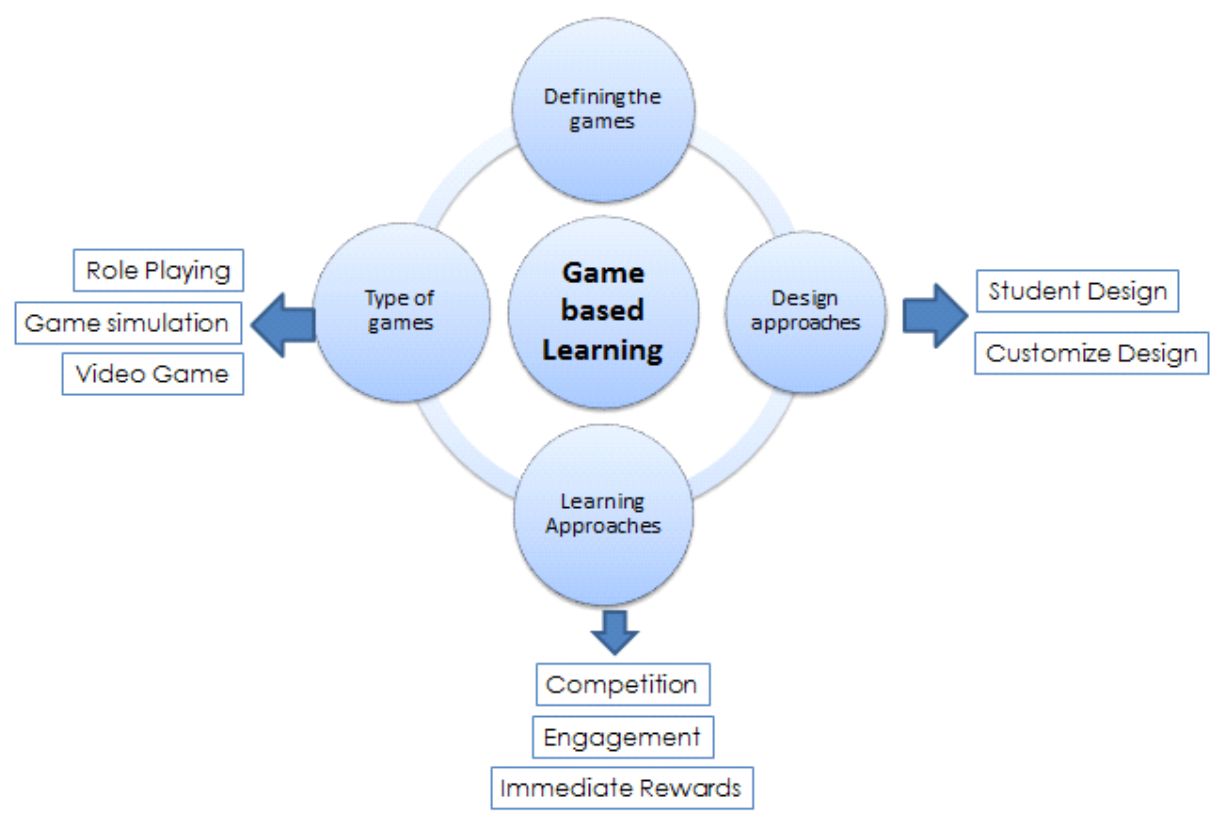

[Fig. 2] Architecture of game based e-learning

The figure 2[7] is the architecture of proposed game based learning. This is very important to consider the design process, learning approaches, defining the games and the type of game to use. Three component must be considered in designing the learning approaches as it the very vital part of the architecture as shown above.

Engagement: 
Generally, the person who plays the game has a habit of continuing to play until one mission is completed. Likewise, when learners become engaged in learning made up of games, they will not stop until the learning ends. This psychological phenomenon is called "intrinsic motivation" by researchers.

\section{Competition:}

The game is played with multiple players, and is played in a way that wins the opponent or opponent team. However, many other games do not require the other player, and they may motivate the player to maintain score or achieve new records. In fact, learning programs are created in a variety of ways, but it's right to compete, but it does not necessarily compete with the other.

\section{Rewards:}

Just as people get a high score in the game or feel satisfied when they reach a higher level, the learners learning through the game are also satisfied if they win or score at a certain level. The learner will play the game once again, even if only a brief reward is given.

Game-based learning plays an important role in helping learners develop using new interactive media. Indeed, the combination of educational design and multimedia has stimulated an exciting game environment for learners to easily participate. The learner can play multiple times to master the game and at the same time modify the lessons learned in the game. The maintenance of lessons learned is taken care of without difficulty.

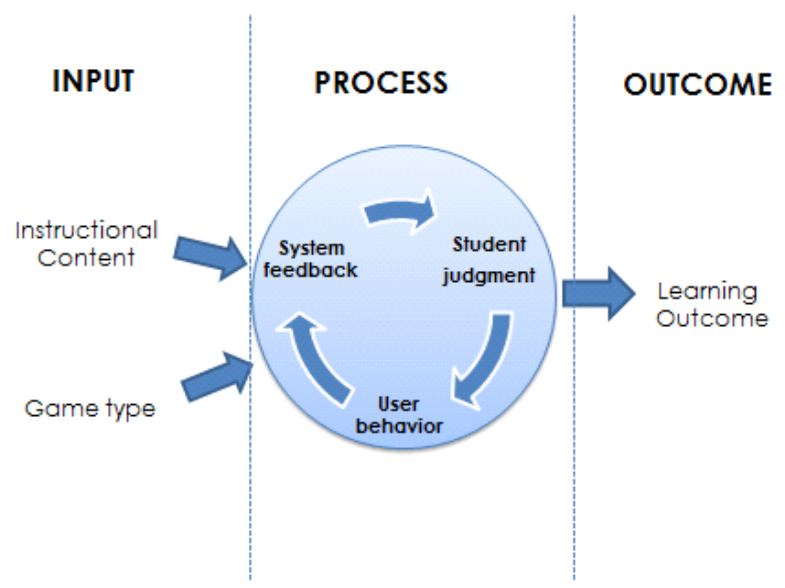

[Fig. 3] Framework of game based e-learning 
The figure 3 shows the framework of game based e-learning. The instructional content, game type represents the input, system feedback, student judgment and user behavior for process and learning outcome for the output.

\section{Physical Protection Requirements}

In the process of preparing for game-based learning, most important factors are overlooked. [8] Because online content is written in digital format, someone can copy or delete it. The most frequent security incidents are to take a game for learning and then modify it to make a similar low-priced game and sell it again. To prevent this, several security techniques such as watermarks have been proposed, but they are not sufficient defense mechanisms. Another important security threat is that it is difficult to determine whether a learner playing a learning game is a real learner. In reality, it is difficult to apply digital security techniques to learning games. Therefore, we should apply physical security techniques at present. Physical security is used as a way to minimize the risk of theft, deletion, copying or destruction. To achieve physical security, decision makers must consider the rules governing buildings, interior layout, emergency procedures, equipment placement and use, power supplies, product handling, and relationships with external contractors and agencies.

Most online learning game providers are not considering security at all. According to the Korea Information and Communications Network Promotion and Information Law, online game providers should also take security measures, and if not, they can be punished according to the law. If the university is providing students with online learning programs, it is necessary to establish and maintain security measures as well, depending on the scale. In the course of this study, we compared and analyzed the systems of various online game providers, but there were not many places to establish and maintain physical measures for information security. These providers did not have any research or suggestions on the physical security measures that they had to set up, nor did they have any particular concerns about how to establish physical security measures. This content will not be included in this paper at the request of providers.

Unfortunately, physical protection requirements are not studied for general evaluation till now, so we should do the research to enhance security level management. 


\section{Conclusion}

The environment of electronic games gives important motivation for persuasive re-engagement by learners and therefore achieves the 'practice makes perfect' scenario. However, most learners don't play educational games because they don't believe that learning comes from playing games and therefore not compelling. Many of the learners in higher education are pre-conditioned to think that games are only wasting their time and not beneficial as a tool for learning as influence by their concerned parents. The well-constructed role-play game can do more that drill and practice, it can help in achieving the needed competencies and skills in many areas of competencies. Therefore, this study presented the noble ideas when designing the game based e-learning to make this engaging, fun and effective for distance learning.

\section{Acknowledgement}

This work was supported by the Sungshin University Research Grant of 2017.

\section{References}

[1] Susan Boyle, An Introduction to Games based learning, (2011), October, UCD Dublin https://www.ucd.ie/t4cms/UCDTLT0044.pdf.pdf, October 2011

[2] Game-Based Learning: What it is, Why it Works, and Where it's Going, http://www.newmedia.org/game-based-learning--what-it-is-why-it-works-and-where-its-going.html, December 19, (2017)

[3] Paul Pivec, Game-based Learning or Game-based Teaching?, http://www.becta.org.uk, July (2009)

[4] Barab, S., Scott, B., Siyahhan, S., Goldstone, R., Ingram-Goble, A., Zuiker, S., \& Warren, S. (2009). Transformational play as a curricular scaffold: Using videogames to support science education. Journal of Science Education Technology, (2009), Vol.18, pp.305-320.

[5] Team, Editorial., What is GBL (Game-Based Learning)?, EdTechReview, Retrieved 2017-03-15.

[6] 6 Basic Benefits Of Game-Based Learning, TeachThought, https://www.teachthought.com/technology/6-basic-benefits-of-game-based-learning/, September 13, (2017)

[7] Chih-Ming Chen, Yen-Nung Tsai, Interactive Location-Based Game for Supporting Effective English Learning, International Conference on Environmental Science and Information Application Technology, (2009), July 4-5, Wuhan, China

[8] https://nces.ed.gov/pubs98/safetech/chapter5.asp, December 19, (2017) 